\title{
Linguagens da favela: diálogo com um Incomodado Social
}

\section{Languages of Slam: Dialogue with a Socially Malcontent}

Gisele Motta Ferreira ${ }^{1}$

O educador e filósofo pernambucano Paulo Freire, patrono da educação brasileira, argumentava uma estreita relação entre pedagogia e comunicação. "Não há inteligência - a não ser quando o processo de inteligir é distorcido - que não seja também comunicação do inteligido. (...) Não há inteligibilidade que não seja comunicação e intercomunicação e que não se funde na dialogicidade" (FREIRE, 1996, p. 17). É dessa forma que se dá a atuação artísticapolítica-pedagógica de Waldemir Correa, 57 anos, fotógrafo, comunicador comunitário, articulador cultural e, antes de tudo, um Incomodado Social, como ele se autodeclara. Com essa multiplicidade há mais de duas décadas "Mimi", como é conhecido, trabalha no Núcleo Sociocultural Caixa de Surpresa ${ }^{2}$, na Vila Aliança, favela da Zona Oeste do Rio de Janeiro.

Passamos, então, para a reprodução de um diálogo registrado em áudio entre Waldemir e Gisele, 28 anos, moradora de Santíssimo e a jornalista que vos fala. Esta entrevista se inspira em uma forma de fazer jornalismo, inserida no movimento do Novo Jornalismo, que teve grande incidência nos Estados Unidos da América nas décadas de 1960 e 1970. Além de criar narrativas para as reportagens e entrevistas, os novos jornalistas se utilizavam de onomatopeias, neologismos, marcas da linguagem oral, gírias e inovações nas pontuações. Na esteira dos novos jornalistas, o Jornalismo Gonzo foi criado por Hunter S. Thompson e tinha como ponto de partida, de forma geral, as inovações de escrita do Novo Jornalismo e, de forma particular, uma escrita altamente política, irônica, marginal e psicodélica. Ele tinha algumas técnicas específicas, como gravar toda a apuração, usar com frequência a transcrição e ter como companheiro um cartunista (Ralph Steadman) ao em vez de um fotógrafo. Essa geração rejeitava a suposta objetividade do jornalismo e o olhar observador, se inserindo no texto. Criavam, assim, reportagens narrativas, abordando temas diversos. Gay Talese e Tom Wolfe, e até mesmo Trumam Capote, tinham uma relação mais forte com o mundo pop, a sexualidade, o glamour, e também com o mundano, a rua, a cidade. Eles são lembrados por algumas obras,

\footnotetext{
${ }^{1}$ Mestre em Comunicação pela Universidade do Estado do Rio de Janeiro (UERJ) e graduada em Comunicação pela Universidade Federal do Rio de Janeiro (UERJ).

2 Entidade sem fins lucrativos na área da cultura. Mais informações disponíveis em: https://www.facebook.com/Ponto-de-Cultura-Caixa-de-Surpresa-667307283332286/. Acesso em: 17 jun. 2020.
} 
como A Fogueira das Vaidades, Fama e Anonimato, Voyer, A Mulher do Próximo, A Sangue Frio e Bonequinha de Luxo. Já Thompson se aproxima de temas menos pop e mais populares e marginais, como gangues de motoqueiros, que retrata em Hell's Angels, corridas de moto e convenções políticas, que cobre em Medo e Delírio em Las Vegas, e um cotidiano de trabalho e de drogas na América Latina, como em Diário de um Jornalista Bêbado. Na verdade, boa parte das obras de Thompson aborda a alteração de consciência, já que Thompson era um entusiasta do uso de psicodélicos e usuário de diferentes tipos de drogas (WOLFE, 2005; TORREY; SIMONSON, 2008; FERREIRA, 2014).

Gisele e Waldemir se conhecem, em 2017, na mobilização cultural do Zona de Cinema, um evento de cinema na praça, na Zona Oeste. O Caixa de Surpresa foi um parceiro fundamental nessa produção cultural, que, mesmo com algum financiamento, era independente por ser de baixíssimo custo e por atuar de forma comunitária. Juntos a outros parceiros, geramos mais de vinte sessões de cinema na Zona Oeste, duas oficinas de audiovisual na Vila Aliança, um curta-metragem, artigos, reportagens, ações sociais, mobilizações e encontros.

O mote dessa conversa, nesse dia que nos encontramos na Vila Aliança, foi: como a favela se comunica, de dentro para dentro e de dentro para fora, e como a comunicação chega, de fora para dentro? Começamos, então, a refletir: há particularidades na forma que as pessoas se comunicam entre si aqui neste território? Como se comunicam fora daqui? Quais aspectos da comunicação das favelas e periferias são considerados e compreendidos por aqueles que criam os discursos oficiais e hegemônicos? Como considerar os não ditos, os tabus e as interdições na comunicação (FOUCAULT, 2011)? Como inserir na discussão sobre diálogo e discurso o corpo como expressão e fala (FURLAN, 2003; NÓBREGA, 2000; HACKNEY, 1988)? Como comparar discursos oficiais, altos, clássicos e os discursos transgressores, marginais, de baixo (STALLYBRASS; WHITE, 1989; BAKHTIN, 1993)? Onde entram os dialetos, as gírias, a moda nos estudos sobre discurso e comunicação? Tudo fala...

Waldemir: É muito rápido na favela, né cara, de olhar, você olha e você já sabe o que tá acontecendo... Você vê um movimento e, caramba, tá acontecendo isso e aquilo... Eu fiquei muito sagaz em favela, assim, né. Você saca rápido! Eu fui convidado a trabalhar o teatro uma vez com uma instituição gringa, a menina que me indicou falou que ia me levar para trabalhar em um lugar que não tinha tráfico de drogas. Eu falei: “O que? No Rio de Janeiro?” Ela falou que era no Alto da Boa Vista... Eu falei: "No Alto da Boa Vista, não tem tráfico de drogas!?" Eu ia ganhar um dinheiro legal, eu fui né... Na hora que eu cheguei no carro com ela, eu já fui olhando, já vi quem era o cara do "Movimento"... Já vi tudo... Ela me apresentou os 
companheiros de trabalho de lá... Em três meses a gente já estava fazendo reunião com famílias que tinham filhos envolvidos com drogas e tal. Ela: "Ih, como você viu isso aqui? Eu já estou aqui há tanto tempo...” Eu falei: “Ah, para... tem coisas que só quem tem o olhar CorpoMovimento que consegue..."

Gisele: Como que tu vê essa linguagem corporal, assim? O que revela quem é quem? Parado na esquina... ${ }^{3}$

Waldemir: É o cotidiano, né? É a forma que você se movimenta, é a forma que você olha, sabe? Como se mexe, tá tudo no corpo... O corpo fala...

Gisele: É uma coisa, tipo, a pessoa tá sempre atenta? Eu acho que tem uma diferença grande das pessoas que são da periferia... Tu já viu aquele filme gringo que tem um mundo em que as pessoas têm um negócio aqui no antebraço que conta o tempo $?^{4}$ E aí quando o cara chega no outro lugar que as pessoas tem um milhão de tempo...

Waldemir: Já! E nego quer roubar o tempo...

Gisele: Eles são sim ladrões de tempo. Mas meu ponto era que as pessoas ricas de tempo, elas andam devagar. Elas têm muito tempo, tá ligado? E no outro lado, que é periferia, as pessoas andam sempre aceleradas. Isso é uma parada muito forte que eu vejo na periferia. Quem é da periferia tá sempre na correria (por isso é "cinema correria" que a gente fala no campo do cinema independente). Cara, tu vive num ambiente hostil, tu não pode ficar relaxado. Existe uma tensão o tempo todo no seu corpo, né?

Waldemir: Sim, tá no seu corpo, você sente o seu corpo pesado... Mas existe seus momentos de relax... São momentos, apenas momentos... Mas que se somados à Vida que se vive no cotidiano de uma favela... putzzz é muito muito massa...

Gisele: Eu tenho uma amiga que falava muito isso... Ela falava: "A minha construção do corpo, eu sofri tanto na minha infância, eu trabalhei tanto que eu sinto dores. Eu trabalho desde os sete anos. Eu posso ficar uma semana sem fazer nada, deitada, mas eu continuo a sentir dores... Sempre, o tempo todo, a dor nunca passa.” É que, tipo, somatiza também, né?

\footnotetext{
${ }^{3}$ Referência ao funk "Parado na esquina", do MC Roba Cena.

${ }^{4}$ Filme estadunidense In Time, traduzido no Brasil como O Preço do Amanhã, lançado em 2011, e dirigido por Andrew Niccol.
} 
Waldemir: Aquele vídeo que tu mandou pra mim... Da menina passando maquiagem. ${ }^{5}$ Eu fiquei ufa! Eu vi a primeira vez, tu vê normal, como se tivesse vendo qualquer coisa... Aí você revê ele, tu vê a profundidade. E aí você relê de novo, caramba, te exacerba, né. Eu recebi um vídeo também de uma menina, que no final ela fala assim: "Se tu ouvir uma mulher gritar, vá lá. Faça alguma coisa! Em briga de marido e mulher se mete a colher sim.” E aí mostra como ela ficou, ela vai se transformando, quando ela apanhou. Pesado, e triste. Pesado e triste e real, né cara. A violência tá aí, tá aqui, tá em todo lugar... E vai moldando os corpos... Já perdi muitas meninas vítimas dessa violência...

Gisele: E esse lance da comunicação da favela com o que é de fora? Como tu vê isso?

Waldemir: Não entendi...

Gisele: A comunicação de dentro para fora, de fora para dentro...

Waldemir: Pô, por eu gostar de trabalhar com teatro, eu sou muito observador, né... E o encontro do asfalto com a favela, assim, sabe? Quando o asfalto entra na favela pra usar droga, ou pra comprar droga ou pra curtir... É como a marola do rio e do mar se encontrando. Você vê a diferença nos corpos mesmo. "Qual é, fala aí cumpade!" [falando alto] "Não, é que..." [tom de voz mais baixo, inseguro] “Não, dá o papo aí cumpade!”... [falando alto] E é aí que tu vê, sabe? E eu, por causa do teatro, eu faço tudo virar cena, tá entendendo? Eu tiro meus personagens das pessoas do cotidiano, e é mágico. Eu já vi nego entrar na favela assim ó, todo gingando, e eu: "Isso não é da favela"... E era polícia, era pila ${ }^{6}$, deu maior merda... Porque existe uma identidade... Eu fui morar no Maranhão... Aí acabou meu beck que levei, parei na porta do hotel, onde eu estava hospedado, vi a praça e fui no cara certo lá! Aí o cara: “Ou, por que você tá falando isso?”... Aí eu: “Ou, eu sou do Rio de Janeiro... Ou você tem ou você sabe quem tem"... E cada favela tem sua leitura do corpo em movimento, né? [rindo] E o meu era do

\footnotetext{
${ }^{5}$ Sobreviver: quanto vale uma vida?, vídeo-poesia criado por Raquel Tavares durante a quarentena da pandemia de COVID-19, em 2020. Disponível em: https://www.youtube.com/watch?v=x3xpY-TsdB0\&feature=youtu.be.

${ }^{6}$ Gíria para a palavra "policial”. Mais informações sobre a questão das gírias de favela em:

A Linguagem da Favela Parte 1: resistência, cultura e identidade, disponível em: https://rioonwatch.org.br/ ?p=13450. Acesso em: 10 abr. 2020.

A Linguagem da Favela Parte 2: o dialeto e o estigma, disponível em: https://rioonwatch.org.br/?p=16516. Acesso em: 10 abr. 2020.
}

A Linguagem da Favela Parte 3: expressões culturais, disponível em: https://rioonwatch.org.br/?p=19293. Acesso em: 10 abr. 2020. 
RJ... Ah, para! Aí ele: "Qual foi carioca, toma uma cerveja comigo?" "Tomo!” E ele era o cara... E depois esse cara me salvou lá... Ele chegou num lugar do nada, onde tinha gente que queria fazer covardia comigo. Porque acontece muito isso no cotidiano da favela... Vira e mexe tem um aí se fudendo na favela... Seja no Rio ou em qualquer outro lugar. Chega na favela, quer usar droga... Vamos supor, chega na favela com 3 mil reais... Vai aparecer um montão de... entre aspas... amigo né... Desce cocaína, desce maconha e cerveja... Chega uma hora que a coisa degringola, nego quer roubar... Já vi o cara entrar com carro e dinheiro na sexta-feira. No domingo, ele tá ligando chorando para a mãe: "Vem aqui me buscar, o carro tá preso aqui na favela..." E alguém rebater: “Tá preso não, você que deixou o carro empenhado por causa da droga..." E eu: "Passa o telefone que eu desenrolo..." Muita das vezes eu fui interlocutor disso, de mediar e falar: "Não, calma, vou chamar a família..." A família vir, pegar o carro... Passava um mês o cara tá aqui de novo... Teve uma menina que entrou na favela na sexta-feira, quando foi na segunda-feira, a família chegou ali... Lembra onde nós levamos aquelas doação? Não era aquela moça ainda não, não era pensão, era um bar... Aí chamaram o cara do bar e o cara do bar me chamou: “Aí, Mimi, tem uma garota aí na favela assim, assim, assado...?” E eu tinha esbarrado com essa menina no sábado à noite... "Tem..." Eu falei: "Ela tá aí sim..." Aí ele falou: “Ó, cumpade, coloca essa menina pra fora se não vai encher, dar treta...” Aí eu falei: "Eu sei onde essa menina tá..." Tava numa rua da favela, dentro da casa de umas outras meninas. Eu falei: "Eu trago ela..." Entrei, falei com as meninas, trouxemos a garota... A garota estava um trapo. Já não tava mais com a roupa bonita, com o sapato bonito, o cabelo bonito... Deve ter ficado sem comer, sem se alimentar, sem dormir, só usando crack, usando droga... Em três dias acabou aquela menina bonita... E isso é uma coisa verídica dentro da favela, isso é real. O mal da droga é real dentro da favela.

Gisele: E a linguagem e a identidade quando o favelado sai da favela? Como tu vê isso?

Waldemir: Eu escrevi uma vez uma coisa... Eu estava trabalhando teatro no contexto de medidas socioeducativas no Degase ${ }^{7}$. E aí, em um encontro na UERJ $^{8}$ para discutir a marginalização de nossos jovens da favela e as truculências, violências e o abandono da instituição Degase, foi colocado pelo representante da Vara da Infância e do Adolescente na

\footnotetext{
${ }^{7}$ Departamento Geral de Ações Socioeducativas, órgão do Governo do Estado do Rio de Janeiro que executa as medidas judiciais aplicadas aos adolescentes em conflito com a lei.

${ }^{8}$ Universidade do Estado do Rio de Janeiro. Waldemir participou de diversas ações e grupos na UERJ, como a Rede Drogas, Aids e Direitos Humanos. Na Universidade Federal do Rio de Janeiro (UFRJ), fez parte do Movimento Consciência Masculina, nos anos 1990 e 2000, que resultou no livro coletivo Palavra de homem, publicado em 2001 pelo NESC/UFRJ:ENSP/FIOCRUZ.
} 
época... Chega ser bizarro... Mas ele falou que, entre aspas, não iam mais prender os garotos. Todo menino que fosse pego com maconha, ele ia até o juiz, e o juiz que ia avaliar ele. Eu intervi, questionei, me indignei, porque sabia que era blá-blá-blá e que nossas crianças e jovens de favela continuariam sendo violentados em seus direitos... Aí eu escrevi uma peça de teatro, na verdade um desabafo, e encaminhei lá no nosso grupo. Era assim: dois garotos de 16 anos. Um descendo o morro pra ir estudar, o outro descendo o elevador para estudar. Um descendo o morro, pá, apertando um baseado e o outro descendo o elevador, pum, apertando o baseado. Na hora que o moleque brota no asfalto, a polícia, pum! Na hora que o moleque sai do portão automático, a polícia, pum, pega ele. Eles vão ser tratados iguais? Não vão, não vão... Isso é fato! Ou, meu irmão! O menino da favela tem uma forma de ser tratado e isso é... tem uma palavra pra isso... Vou usar a palavra normal por falta de uma melhor, porque não pode ser normal...

Gisele: Normativo?

Waldemir: É... O menino da favela, quando tá fora da favela, ele é facilmente identificado. E na favela muitas vezes ele dura pouco... Eu já perdi muitos meninos aqui... Eu fui um moleque virado no caralho. Quando eu tinha 14 anos, eu era virado no caralho. Eu usava droga pesada, tinha que bancar droga pesada... E eu ia pra Zona Sul, para as faculdades, circulava por todos os lugares...

Gisele: E como você era visto nesses lugares? Como você interagia?

Waldemir: Eu não sei, eu não tenho religião, mas, se existe um Deus, esse cara se amarra na minha... Parece que ele me pinça assim e pum, pum... Todo mundo se amarrava na minha.

Gisele: Assim, tu acha que tu foi um jovem típico da favela?

Waldemir: Meu pai trabalhava embarcado, viajava para fora do país, trabalhando. Eu morava no asfalto. Meu pai era da elétrica... força e controle, usinas de energia... Ele atuava junto aos movimentos trabalhistas da época... É minha bagagem histórica... Aqui, onde hoje é favela, era sítio naquela época, era completamente diferente, saca?... Meu pai e seus irmãos cresceram livres nos campos e rios da época, aqui onde hoje é tudo valão, eu ainda vivi o finalzinho disso...

Gisele: Tipo, tu morava num lugar que a favela engoliu... 
Waldemir: O muro lá de casa era desse tamanhinho, eu não podia brincar com os meninos [da favela]. Só podia brincar com os garotos que moravam ali mesmo, que iam para minha casa, porque minha casa tinha televisão, tinha som... Era o único lugar que tinha... Mas quando eu pulei o muro pela primeira vez, fudeu... Eu fui pra favela e falei: "Caraca! Isso aqui é muito bom..." Quer dizer, o povo já me conhecia dali, eu era cabeludo... Imagina, 13/14 anos, cabeludão, nunca tinha cortado o cabelo... Todo mundo gostava de mim, fui usando todas as drogas, tinha dinheiro, meu pai me dava mesada... Eu ia com os moleques para a feira para fazer carreta pra tá junto com eles.

Gisele: O que é fazer carreta?

Waldemir: Antigamente a gente ia com carrinho de rolimã e colocava a feira das madames daqui no carrinho e trazia... E aí eu conheci os melhores e os piores aqui... E isso me deu muito alicerce... A primeira vez que eu fui pego pela polícia, quando eu cheguei na delegacia, o delegado era amigo de infância do meu pai... Ele ralhou comigo, me deu maior trato, falou que ia falar com meu pai... Quando meu pai chegou de viagem, eu falei pra ele o que tinha acontecido... E ele: "Pô, Mimi..." Eu não me esqueço até hoje... Ele falou: "Errar é fazer coisas erradas na hora errada com pessoas erradas. Se você errar com pessoas certas na hora certa, você acaba até aprendendo..." Aí eu comecei a avaliar com quem eu fícava, tá entendendo? Aí a vida foi indo, me protegendo... Eu nunca gostei de estudar... Não achava estudar legal, não gostava de ir para a escola, sabe? Mas acredito ter frequentado quase todas as universidades e faculdades do estado [rindo]. Clandestinamente e subversivamente, claro... [rindo] Eu estudava em escola particular, gastava o dinheiro todo da mensalidade com droga... Meu pai me dava dinheiro para pagar a escola, eu fazia festa. Eu aprendi de outras formas, muitas coisas na vida...

Gisele: E hoje em dia tu se vê com uma identidade favelada?

Waldemir: Eu não... Eu acho que a palavra favelado ela é depreciativa, pejorativa, sabe? Ela é até para criar essa divisão, esse apartheid. Eu me identifico como Incomodado Social. Eu vivo os dois mundos. Eu vivi o mundo fora da favela, vários glamours... Podia ter fícado no glamour, mas me sentia mais acolhido, uma relação mais verdadeira com a favela... Mas nunca fui empregado de tráfico, nunca! Nunca tive problemas com eles... Uma vez um cara veio me questionar em um encontro de lideranças comunitárias: "Mimi, você nunca fala mal do tráfico". “Claro, eu trabalho com cultura, vou falar de tráfico? Você trabalha pra eles, eu não! Ou!” Aí 
eu racho com os movimentos, com as instituições... Instituição que cria pasta para legitimar liderança comunitária e só tem bandido na pasta? Só pilantra! Não quero essa legitimação de liderança comunitária, não preciso... Eu me nego a ser reconhecido e me reconhecer como liderança comunitária... E hoje você vê aí as lideranças comunitárias corrompidas na favela... Não todos, mas vários!

Gisele: Mas, e essa questão da diferenciação, por mais que a gente possa estar nesse movimento de transgredir isso, de virar e falar, não eu não quero esse rótulo, essa caixinha, ao mesmo tempo, a sociedade mesma, ela impõe... E muitas pessoas hoje elaboram o termo favelado como uma identidade própria, positivada.

Waldemir: Na minha opinião, isso prevalece, a segmentação, e favorece "Eles" "9 "Eles" mesmo que criam para dividir... Por este motivo, somado às atitudes destes que nos legitimam favelados dentro de nossas favelas, é que eu racho e não aceito algumas pessoas e instituições dentro e/ou fora de nosso território... Os vampiros que se alimentam do caos e do sofrimento de muitos...

Gisele: Você acha que a gente consegue se aproveitar disso de alguma forma? Usar essas categorizações também para nos proteger? No sentido de: esse cara é branco, burguês, explorador de mão de obra, capitalista, se ele puder me fuder, ele vai...

Waldemir: Eu nego a segmentação. Não é: “Ah, porque é branco”, “Ah, porque o negro na favela..." A porrada tá comendo em negros e brancos. Hoje a favela não é só de negros, hoje o gueto não tem só negros, tá entendendo?

Gisele: Mas e se a gente for pensar nos brancos? Que estão controlando o rolê? Isso que eu quero pensar, porque as minorias [ou minorias-maiorias] estão se fudendo cada um a sua maneira... Mas querendo ou não tem muito pouco preto no poder. Tem muito pouco viado no poder. Quem tá no poder são brancos, ricos e heteronormativos...

Waldemir: São muitos poderes, diferentes poderes... A Polícia Militar atua frente a um tipo de poder do Estado que efetivamente chega na favela. Agora você tenta me responder: Por que

\footnotetext{
9 "Eles" é como ele se refere aos "donos" do sistema, os que conseguem criar os discursos hegemônicos, os dominantes nas relações de poder.
} 
quando o negro... Me ajuda a entender... Por que quando o negro vira polícia, quando entra na favela, é o que mais bate nos pretos da favela?

Gisele: Não sei... Não sei mesmo! Eu tava lendo uma coisa sobre isso, mas não lembro quem era a pesquisadora... ${ }^{10}$ Ela falava que o tipo de corporação que é a Polícia Militar hoje, ela cria uma identidade, que é uma identidade de bando que substitui a identidade de negro, a identidade racial. Então, o negro da Polícia Militar, acima de ser negro está ser polícia, porque é uma identidade grupal muito forte... Então, tipo assim, ele não consegue se identificar, ele não olha pro favelado e vê o seu igual a nível racial, ele olha e vê o seu diferente enquanto alguém que não pertence à sua corporação. Se não for do grupo, da alcateia, da casta, do clã, do cartel deles... eles não se identificam... Como o jovem da favela é visto fora da comunidade, nós já sabemos...

Waldemir: São totalmente marginalizados...

Gisele: Mas como eles são tratados e agem e se comunicam dentro da favela?

Waldemir: Isso é muito delicado... Não existe uma regra $\mathrm{X}$ de como a criança vai crescer dentro da comunidade, tem muito a ver com a forma que ela se relaciona com a própria família... Eu já vi amigos meus responsa perder o filho para o tráfico, jovens que estudavam em escola particular, que tinham tudo em casa... Perderam primeiro para o tráfico e depois para as forças de segurança. Garotos jovens, com menos de 18/19 anos, com um futuro pela frente... Tem a ver como esse jovem caminha dentro da comunidade. A forma que ele caminha na comunidade vai dizer como ele vai ser tratado dentro da comunidade... Essa comunidade que o pariu, que o viu crescer, que o cria. E são linhas tênues, são questões de segundos e minutos, as coisas mudam para crianças na favela. Eu fui criança na favela, tá entendendo? A primeira vez que eu peguei droga para alguém, só pra eu fumar também, eu quase morri. E ainda levei um soco na cara do meu primo, fiquei quase um mês sem entrar na favela, eu falo disso com ele até hoje... E daquele dia em diante eu nunca mais peguei droga para ninguém pra eu usar... Só que nós temos jovens adultos e jovens crianças que pegam droga para outras pessoas para usar e acabam virando aviãozinho ${ }^{11}$. Aí a relação com esse jovem já é outra... São várias formas de jovens na comunidade, então são várias formas de lidar com o jovem na comunidade, de ver

\footnotetext{
${ }^{10}$ Se alguém tiver referência desse estudo, mandar para gisele.motta@outlook.com. Não consegui achar até o fechamento desta entrevista.

11 “Aviãozinho" é a gíria para os trabalhadores do tráfico que ficam encarregados das entregas para o comprador.
} 
o jovem... Eu acredito que eu fui visto na favela como um jovem totalmente rebelde, marginal... Quem me conheceu criança não achava que eu ia passar dos 18... Eu desrespeitei uma série de questões e consegui sobreviver, mas tem um montão que não conseguiu... Existe uma coisa na favela, que você não ensina o moleque da favela, você compartilha o que você acha legal, o que você acha que é certo. E a partir do seu compartilhamento, da forma que você aborda esse jovem, ele vai ou não te ouvir... Eu fui um privilegiado, com o compartilhamento da linguagem cultural, vários jovens me ouviram... Eu fico lisonjeado, quando eles passam e me cumprimentam e escolheram não ser empregados da "Firma". Mas foi uma opção deles... Mas também já perdi muitos meninos e meninas, muitos mesmo... Por mais que nós não tenhamos políticas públicas, nós temos opções na favela, não existe isso de que todo jovem tem que [ir para o tráfico]... Ao mesmo tempo, a comunicação dentro da comunidade, a comunicação dos jovens, jovem, tráfico, futebol, baile, dança, essas coisas se fundem, tá entendendo? Hoje quem tá no tráfico jogava bola ou dançava pra caramba, então tem toda uma interlocução muito fácil... Eu gosto de trabalhar muito em campo de futebol, porque para mim é o encontro entre vários atores... O jovem que virou bandido, o que virou bandido e agora é pai, o jovem que jogava muita bola, agora não joga mais, mas o filho dele joga... Ou o primo dele joga, então ele é dono de um time de futebol... E é uma comunicação específica do jovem com o tráfico, é quase normal... Hoje quase não tem gente cascuda no tráfico, com 20 anos você já tá velho no tráfico, é realmente muito menino novo operando a máquina... E como que esse tráfico vai olhar esse jovem? O tráfico olha esse jovem como aviãozinho? Como putinha? ${ }^{12}$ Ou como alguém que canta, que dança, potente, talentoso? Ou não? Esse jovem é fútil, não tem nada na cabeça? A forma que esse jovem se mostra dentro desse cotidiano de favela e na relação com o tráfico é que mostra quais caminhos esse jovem vai trilhar... Qual vai ser o grau de respeitabilidade e confiabilidade... Depende de muita coisa... Tem gente aqui na favela que ninguém dá nem dinheiro pra comprar o pão, porque sabe que o pão não vai voltar...

Gisele: E a comunicação?

Waldemir: A linguagem da favela é foda, porque você não precisa dizer que o cara é um vacilão, né... Você não precisa dizer que o cara é um filha da puta... Basta você dizer: "Ih, ó o cara..." "Ih, alá! Mó... Putz!"... As expressões elas têm uma leitura, é muito doido esta leitura... Parando para pensar, eu penso, é uma comunicação muito rápida, só de olhar você já sabe o que ele quer dizer... "Pô, filha da puta" pode ser diversas coisas, o cara é responsa, ou

\footnotetext{
${ }^{12}$ Meninos e meninas que se prostituem para o tráfico ou em parceria.
} 
que o cara não presta... E aí rapidamente é um entendimento, você fala a mesma coisa, mas ela pode ser compreendida de várias formas, dependendo de como você emprega os termos. "Ih, alá o cara", dependendo de quem é o cara e a situação, vai ser uma coisa... O entendimento é de acordo com o ambiente, com o contexto... "Vamos dar um rolê, uma baqueada"13... "Vamos dar um, dar dois, dar três"... O dialeto da favela é foda... Eu jurava que eu não falava gíria e aí eu trabalhei em Minas Gerais e eu conheci uma menina e ela gostou muito de mim e eu acabei indo na casa dos pais dela. E o pai dela falou assim pra mim: “Ô carioca, você não vai namorar minha filha, você não para de falar gíria”... Aí eu falei: "Que isso, qual foi? Ih alá, eu falo gíria? Aonde?” Mas era apenas a forma que no Rio de Janeiro a gente se comunica... Quando o Raul [filho] era jovem, ele gostava muito de lan house, então eu criei uma lan house aqui na favela, chamado "Surfando na Rede". Consegui juntar vários jovens inteligentes dentro dessa questão, e tinham um negócio, um tal de orkut que eu não conseguia entender o que eles escreviam, era tudo abreviado, era tudo rápido, tec, tec, tec... É uma linguagem à parte, né?

Depois de mais de uma hora trocando essa ideia, Gisele e Waldemir se despediram sem beijos nem abraços. O isolamento por conta da pandemia causada pelo novo coronavírus tinha acabado de começar, e estamos desde então aprendendo esses novos condicionamentos corporais e comunicacionais. Principalmente os idosos e os periféricos, os excluídos digitais, estão tendo que se readaptar ou se adaptar a essa "linguagem à parte", que agora vem sendo a principal fonte de comunicação entre aqueles que estão conseguindo se autoisolar. Seguimos conectados! E, embora pareça que isso se refere às mídias digitais, é de outra instância de conexão que estamos falando, que nos unifica diariamente e percorre caminhos energéticos diferentes da eletricidade.

\section{Referências bibliográficas}

BAKHTIN, Mikhail. A cultura popular na Idade Média e no Renascimento: o contexto de François Rabelais. São Paulo/Brasília: EdUNB, 1993.

FERREIRA, Gisele Motta. Jornalismo literário e mídias digitais: a questão do experimentalismo: do jornalismo Gonzo às reportagens multimídias. 2014. 56f. Trabalho de Conclusão de Curso (Graduação em Comunicação - Habilitação em Jornalismo) - Escola de Comunicação, Universidade Federal do Rio de Janeiro, Rio de Janeiro, 2014.

\footnotetext{
${ }^{13}$ Nesse contexto, "baqueada" é gíria para uso de drogas.
} 
FOUCAULT, Michel. A Ordem do Discurso: aula inaugural no Collège de France, pronunciada em 2 dez. 1970. São Paulo: Loyola, 2011.

FREIRE, Paulo. Pedagogia da autonomia: saberes necessários à prática educativa. São Paulo: Paz e Terra, 1996.

FURLAN, Reinaldo; BOCCHI, Josiane. O corpo como expressão e linguagem em Merleau-Ponty. Estudos de Psicologia, v. 3, n. 8, p. 445-450, 2003.

HACKNEY, Peggy. Moving Wisdom: the role of the body in learning. Context, n. 13, p. 26-29, 1988.

NÓBREGA, Terezinha. Merleau-Ponty: o corpo como obra de arte. Princípios, n. 8, v. 7, p. 95108, jan.-dez., 2000.

PENA, Felipe. Jornalismo literário. São Paulo: Contexto, 2004.

STAllybRASS, Peter; WHITE, Allon. Politics and Poetics of Transgression. Cambridge: University Press, 1989

THOMPSON, Anita. The Gonzo Way: a Celebration of Dr. Hunter S. Thompson. Colorado: Fulcrum Publishing, 2007. 112p.

TORREY, Beef; SIMONSON, Kevin (Org.). Conversations with Hunter S. Thompson. Oxford: University Press of Mississipi, 2008. 215p.

WOLFE, Tom. Radical chique e o novo jornalismo. São Paulo: Companhia das Letras, 2005. 246p. 